\title{
Corneal angiogenesis based on different protocols of alkaline cauterization in murine models ${ }^{1}$
}

\author{
Flor Diana Yokoay Claros-Chacaltana', Karina Kamachi Kobashigawa", Ivan Ricardo Martinez Padua'", \\ Gisele Pereira Valdetaro'v, Marcela Aldrovaniv, José Luiz Laus ${ }^{\mathrm{VI}}$
}

'MSc, Fellow PhD degree, Ophthalmology Unit, Department of Veterinary Clinical Medicine and Surgery, Faculty of Agrarian and Veterinary Sciences, Universidade Esatdual de São Paulo, FCAV-UNESP, Jaboticabal-SP, Brazil. Conception and design of the study; acquisition, analysis and interpretation of data; manuscript writing.

"MS, Fellow PhD degree, Ophthalmology Unit, Department of Veterinary Clinical Medicine and Surgery, Faculty of Agrarian and Veterinary Sciences, FCAV-UNESP, Jaboticabal-SP, Brazil. Acquisition, analysis and interpretation of data; critical revision.

I'PhD, Ophthalmology Unit, Department of Veterinary Clinical Medicine and Surgery, Faculty of Agrarian and Veterinary Sciences, FCAV-UNESP, Jaboticabal-SP, Brazil. Acquisition of data, critical revision.

IVMS, Ophthalmology Unit, Department of Veterinary Clinical Medicine and Surgery, Faculty of Agrarian and Veterinary Sciences, FCAV-UNESP, Jaboticabal-SP, Brazil. Acquisition of data, critical revision.

${ }^{\vee} \mathrm{PhD}$, Ophthalmology Unit, Department of Veterinary Clinical Medicine and Surgery, Faculty of Agrarian and Veterinary Sciences, FCAV-UNESP, Jaboticabal-SP, Brazil. Analysis and interpretation of data, critical revision, final approval.

$V^{V I P h D}$, Associate Professor, Ophthalmology Unit, Department of Veterinary Clinical Medicine and Surgery, Faculty of Agrarian and Veterinary Sciences, FCAV-UNESP, Jaboticabal-SP, Brazil. Critical revision, final approval.

\section{Abstract}

Purpose: To establish and compare protocols of alkaline cauterization for inducing corneal angiogenesis in murine models.

Methods: Twenty-four adult Wistar rats were distributed into four groups (G1, G2, G3, and $\mathrm{G} 4)$. The right eye cornea from each rat was cauterized using filter paper (3 $\mathrm{mm})$, soaked in a solution of silver and potassium nitrates (3:1). Cauterization times were 10 (G1 and G4), or 20 seconds (G2 and G3). Cauterized corneas were washed with Ringer's lactate solution. The filter paper was either removed before washing ( $G 1$ and $G 2$ ), or kept on the corneas ( $G 3$ and G4). Corneas were photographed at multiple time points $(2,4,6,8,11,13$, and 15 days after the procedure), and neovascularization parameters were assayed.

Results: Neovascularization was observed in $66 \%$ of G1 corneas, and $100 \%$ of G2, G3, and G4 corneas. On day 15, G1 corneas showed smaller vascularized areas (12.63 $\pm 12.59 \%)$ compared to those in the G3 $(41.95 \pm 17.32 \%)$ and $G 4(33 \pm 11.74 \%)(P<0.05)$ groups.

Conclusions: The silver and potassium nitrate solution effectively induced corneal angiogenesis. The G2, G3, and G4 protocols showed excellent reproducibility, and induced vascularization in $100 \%$ of corneas.

Key words: Corneal Neovascularization. Cautery. Silver. Rats. 


\section{Introduction}

Angiogenesis represents the formation of new blood vessels from the preexisting vasculature ${ }^{1-3}$. In mammals, angiogenesis occurs during embryonic development and continues, in some tissues and organs, during postnatal life. In adult animals, the angiogenic process is related to the cyclical events of the female reproductive cycle (ovulation and pregnancy). Under controlled physiological conditions, angiogenesis contributes to tissue repair and to inflammatory responses ${ }^{4,5}$.

The molecular mechanisms that regulate angiogenesis change during the development of many pathological conditions, which are collectively known as angiogenesisdependent. In ophthalmology, for example, the exacerbation of the angiogenic process is associated with the development of many postoperative conditions or complications, such as corneal neovascularization, neovascular glaucoma, central retinal vein occlusion, corneal graft rejection, retinopathy of prematurity, diabetic retinopathy, agerelated macular degeneration, and tumor progression $^{2,3}$.

Many studies have focused on the elucidation of the mechanistic basis of angiogenesis, as well as on the development of drugs capable of blocking the progression of angiogenesis-dependent diseases, especially cancer ${ }^{2,3,6}$. Therefore, angiogenesis models are being utilized for in vitro applications, and in preclinical trials. The cornea has been widely used as a model for preclinical studies involving proangiogenic or anti-angiogenic molecules. Due to its transparency and anatomical location, it facilitates the monitorization of vascular responses, and allows their quantification using biomicroscopy. Different protocols have been proposed for the experimental induction of angiogenesis in the cornea ${ }^{6-9}$.
Considering the heterogeneity of organic tissues and the complexity of the cellular reactions involved in angiogenesis, the choice of the model should always consider the objectives of the study, and the characteristics (e.g., time of action) of the alleged modulator drug being tested ${ }^{10}$.

Protocols involving alkaline cauterization represent a good option for the induction of corneal angiogenesis, given the cost-benefit. However, some authors report unsatisfactory results after using these protocols, as not all corneas develop angiogenesis. The reproducibility of corneal cauterization protocols using alkali remains controversial. While in some studies, alkaline cauterization appears to be very effective in the induction of corneal neovascularization, in others, the lack of reproducibility in the vascular response represented a limiting factor for the validation of the results ${ }^{10}$.

We hypothesized that variations in the alkaline cauterization steps, especially in the time of exposure of the cornea to the cauterizing agent, and in the type and size of the instrument used for cauterization, could lead to different vascular responses, thus compromising the reproducibility of the inter-observer results. In the literature, corneal cauterization times with alkali using a combination of $75 \%$ silver and $25 \%$ potassium nitrate range from 8 to 60 seconds $s^{8,11-16}$. The cauterizing instrument is usually a stick or filter paper, whose diameter ranges from $1.8 \mathrm{~mm}$ to $5 \mathrm{~mm}^{8,11-16}$.

The aim of this study was to establish and compare the effectiveness of four alkaline cauterization protocols (with silver and potassium nitrate) in the induction of angiogenesis in rat corneas. Several parameters of corneal vascularization were evaluated and compared between the study groups and at different time points after the procedures. 


\section{Methods}

\section{Animals and procedures for alkaline cauterization}

This study adhered to the rules of the Association for Research in Vision and Ophthalmology-ARVO (Statement for the Use of Animals in Ophthalmic and Visual Research). The ethical principles established by the National Institutes of Health Guide for the Care and Use of Laboratory Animals (NIH Publications No. 8023, revised 1978) were followed. The study protocol was approved by the Ethics Committee on Animal Use (protocol number 06174/14) of FCAV/UNESP, Jaboticabal.

Twenty-four male rats (Rattus norvegicus, Wistar lineage), aged between 3 and 4 months, from the vivarium of the General Administration, UNESP, were used in this study. As inclusion criteria, the ocular examination included slit-lamp biomicroscopy (Nidek Co, SL450, Aichi, Japan) and the fluorescein sodium dye test (Ophthalmos, Sao Paulo, Brazil). All animals were free of signs of eye disease ${ }^{17}$. The rats were divided into four groups $(n=6)$, designated as $\mathrm{G} 1, \mathrm{G} 2, \mathrm{G} 3$, and $\mathrm{G} 4$. The animals were fed a commercial pellet diet $(65.82 \%$ carbohydrate, $5.36 \%$ fiber, $21.0 \%$ protein, and $4.96 \%$ fat) and they received water ad libitum.

The procedures for the induction of corneal angiogenesis were performed on animals under dissociative anesthesia ${ }^{18}$. Antisepsis was performed, and proxymetacaine eye drops (Alcon, Sao Paulo, Brazil) were instilled to promote desensitization of the ocular surface.

For alkaline cauterization, a circular piece of filter paper, with a diameter of $3 \mathrm{~mm}$, embedded in a solution of $75 \%$ silver nitrate (Synth, Diadema, Brazil) and 25\% potassium nitrate (Dinâmica, Contemporary Chemistry Ltda., Diadema Brazil), was pressed onto the axial region of the cornea, in the right eye of each animal. The contact time of the filter paper with the cornea was 10 seconds for the $\mathrm{G} 1$ and $\mathrm{G} 4$ groups and 20 seconds for the $\mathrm{G} 2$ and $\mathrm{G} 3$ groups. After cauterization, the corneas were washed with lactated Ringer's solution for 1 minute. In the $\mathrm{G} 1$ and $\mathrm{G} 2$ groups, the filter papers were removed immediately before washing the cornea. In the G3 and G4 groups, the corneas were washed in the presence of the filter paper. Post-cauterization, the animals subcutaneously received tramadol hydrochloride $(5 \mathrm{mg} / \mathrm{kg})$ as an analgesic, every 8 hours, for 10 days.

The eyes were examined after 2, 4, 6, 8, 11,13 , and 15 days post-cauterization, to monitor the vascular response ${ }^{2,22}$. The examinations were performed after the instillation of anesthetic eye drops. Pupillary dilatation was achieved by instillation of $1 \%$ tropicamide (Alcon, Sao Paulo, Brazil). The fluorescein sodium dye test was also used (Ophthalmos, Sao Paulo, Brazil). The presence of edema, corneal ulcer, corneal melting, synechiae, and hypopyon were noted. During the clinical evaluations, the corneas were immediately photographed (laterally and frontally), using digital equipment (TRC-50DX, Topcon, Japan) with a green filter (red free) and without a filter.

Side view images of corneas, photographed at different time points during the postoperative evaluation, were studied by a single examiner, who measured the burn intensity ${ }^{19}$. This was scored based on the appearance of blisters and on the extent of their elevation from the corneal surface $(0=$ no blister; $1=$ a small blister that is slightly raised above the surface; 2 = a medium blister that is moderately raised above the surface; 3 = a large blister).

\section{Evaluation of corneal vascularization parameters}

Three parameters were evaluated: the development of neovascularization, the neovascularization profile, and the percentage of the corneal area occupied by vessels. Data 
were collected using frontal profile images of corneas and a green filter (red free). All evaluations were qualitative and quantitative, and were performed by a single examiner.

To assess the development of neovascularization, the extent of new vessel development in the cauterized eyes was graded using the following scores: negative (0), when no new vessels were visible; mild (1), when dense new blood vessels were present at the limbus; moderate (2), when the growth of new blood vessels extended from the limbus towards the periphery of the cauterized site; and severe (3), when new blood vessels reached the cauterized site ${ }^{20}$.

The neovascularization profile data received scores in the $0-3$ range per corneal quadrant, with increments of 0.5 , using a grid system based on the centripetal extent of the outgrowth of the neovascular branch from the corneoscleral limbus. The scores for each corneal quadrant were summed for each eye, to obtain the index of corneal neovascularization (range, 0-12) ${ }^{21}$.

The percentages of the corneal areas that were occupied by vessels were calculated using the ImageJ software (http://imagej.nih. gov/ij/; National Institutes of Health, Bethesda, MD, USA ${ }^{22}$. A test system containing 110 points was positioned over the photographic images $^{9,23}$. The percentage of the area that was occupied by vessels was calculated with the (PV $\times 100$ )/PC formula, where PV represents the number of points that touch the vessels, and $P C$ represents the number of points that touch the corneas.

\section{Statistical analysis}

Quantitative variables were analyzed using parametric [analysis of variance (ANOVA), single ANOVA, and repeated measures ANOVA, followed by Tukey's post-hoc test] and nonparametric tests [Kruskal-Wallis (KW), with Dunn's post-test]. Differences were considered significant when $\mathrm{P}<0.05$. The evaluations were done using the MedCalc statistical software (MedCalc ${ }^{\circledR}$, Mariakerke, Belgium).

\section{- Results}

All eyes presented edema at days 2 and 4 , during the evaluations. The occurrence of edema declined in subsequent evaluations. One eye in the G2 (16.6\%) and one eye in the G3 groups (16.6\%) displayed corneal melting in the evaluations at days 4 and 6 , respectively. One animal in the $G 2$ group was euthanized. Synechiae were observed in the G3 group, at day 11 (1 eye, 16.6\%) and day 15 ( 2 eyes, 33.3\%) of the evaluation. In all groups, some eyes presented corneal ulcer at the initial stages of the evaluation. Two eyes in the $\mathrm{G} 4$ group (33.3\%) presented hypopyon, during the evaluation at day 2 .

Neovascularization (measured as a cumulative rate) was present in $16.66 \%$ of the corneas on day $6,50 \%$ of the corneas on day 8 , and $66.66 \%$ of the corneas on day 11 , in the $\mathrm{G} 1$ group. In the $\mathrm{G} 2$ group, neovascularization was present in $16.66 \%, 33.33 \%, 50 \%$, and $100 \%$ of corneas on days $2,4,8$, and 11 , respectively. In the G3 group this occurred in $16.66 \%, 33.33 \%$, $66.66 \%$, and $100 \%$ of the corneas on days 2 , 6,11 , and 13 , respectively, whereas in the $\mathrm{G} 4$ group $16.66 \%, 83.33 \%$, and $100 \%$ of the corneas presented neovascularization on days 4, 8 and 11 , respectively.

The burn intensities (Figure 1), at the different evaluation times and in the various groups included in the study, are presented in Table 1. Corneas in the G2, G3, and G4 groups showed an enhanced burn intensity when compared to the corneas in the $\mathrm{G} 1$ group $(\mathrm{P}<$ 0.05). 


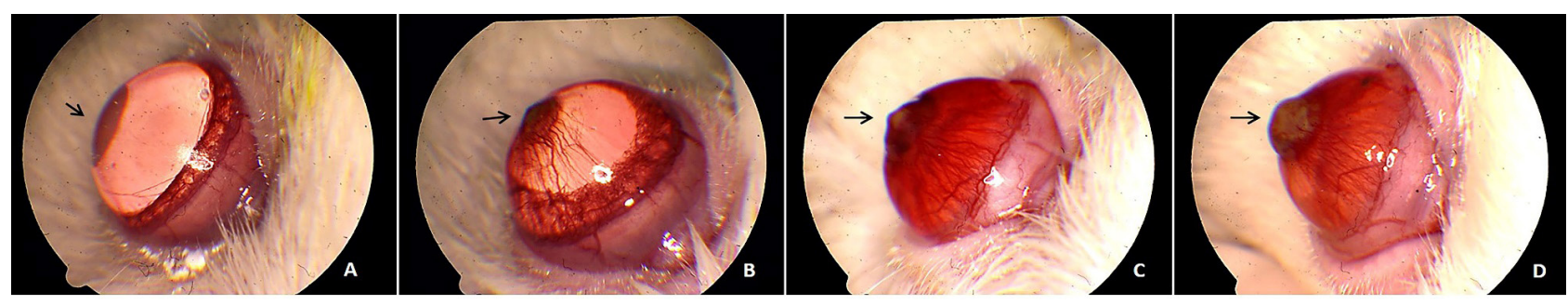

Figure 1 - Images of corneas with burn intensity due to corneal cauterization induced by alkali (arrows). Grade 0 (A), 1 (B), 2 (C), and 3 (D) (Veterinary Ophthalmology Service, UNESP/FCAV, Jaboticabal, SP, Brazil 2017).

Table 1. Mean values with standard deviation, median, minimum, and maximum values, representing the burn intensity gradation in the $\mathrm{G1}, \mathrm{G} 2, \mathrm{G} 3$, and $\mathrm{G} 4$ groups, on days 2, 4, 6, 8, 11, 13, and 15. Veterinary Ophthalmology Service, UNESP/FCAV, Jaboticabal, SP, Brazil 2017.

\begin{tabular}{|c|c|c|c|c|c|c|c|c|c|c|c|c|c|c|c|c|}
\hline Day & $\begin{array}{l}\text { G1 } \\
(n=6)\end{array}$ & & & & $\begin{array}{l}G 2 \\
(n=6)\end{array}$ & & & & $\begin{array}{l}\text { G3 } \\
(n=6)\end{array}$ & & & & $\begin{array}{l}\text { G4 } \\
(n=6)\end{array}$ & & & \\
\hline & $\begin{array}{l}\text { Mean } \pm \\
\text { sd }\end{array}$ & $x$ & $\min$ & $\max$ & $\begin{array}{l}\text { Mean } \pm \\
\text { sd }\end{array}$ & $x$ & $\min$ & $\max$ & $\begin{array}{l}\text { Mean } \pm \\
\text { sd }\end{array}$ & $x$ & $\min$ & Max & $\begin{array}{l}\text { Mean } \\
\pm \text { sd }\end{array}$ & $x$ & $\min$ & $\max$ \\
\hline 2 & $\begin{array}{l}0.67 \pm \\
0.52\end{array}$ & 1 & 0 & 1 & $\begin{array}{c}0.67 \pm \\
0.52^{*}\end{array}$ & 1 & 0 & 1 & $\begin{array}{l}1.5 \pm \\
0.84^{*}\end{array}$ & 1 & 1 & 3 & $\begin{array}{l}1.67 \\
\pm \\
0.82\end{array}$ & 1.5 & 1 & 3 \\
\hline 4 & $\begin{array}{l}0.33 \pm \\
0.52\end{array}$ & 0 & 0 & 1 & $1.5 \pm 1.23$ & 1 & 0 & 3 & $\begin{array}{l}1.33 \pm \\
1.03\end{array}$ & 1 & 0 & 3 & $\begin{array}{l}1.17 \\
\pm \\
0.99\end{array}$ & 1 & 0 & 3 \\
\hline 6 & $\begin{array}{l}0.17 \pm \\
0.41\end{array}$ & 0 & 0 & 1 & $\begin{array}{l}1.67 \pm \\
1.21\end{array}$ & 1.5 & 0 & 3 & $\begin{array}{l}1.83 \pm \\
1.33\end{array}$ & 2 & 0 & 3 & $\begin{array}{l}1.17 \\
\pm \\
0.99\end{array}$ & 1 & 0 & 3 \\
\hline 8 & $\begin{array}{l}0.33 \pm \\
0.82 * *\end{array}$ & 0 & 0 & 2 & $\begin{array}{l}1.33 \pm \\
1.37\end{array}$ & 1 & 0 & 3 & $\begin{array}{l}2.33 \pm \\
0.82^{* *}\end{array}$ & 2.5 & 1 & 3 & $\begin{array}{l}1 \pm \\
1.1\end{array}$ & 1 & 0 & 3 \\
\hline 11 & $\begin{array}{l}0.33 \pm \\
0.52^{* *}\end{array}$ & 0 & 0 & 1 & $1.2 \pm 0.84$ & 1 & 0 & 2 & $\begin{array}{l}2 \pm \\
1.1^{* *}\end{array}$ & 2 & 1 & 3 & $\begin{array}{l}1 \pm \\
1.1\end{array}$ & 1 & 0 & 3 \\
\hline 13 & $\begin{array}{l}0.17 \pm \\
0.41^{* *}\end{array}$ & 0 & 0 & 1 & $1.2 \pm 0.84$ & 1 & 0 & 2 & $\begin{array}{l}2 \pm \\
0.9 * *\end{array}$ & 2 & 1 & 3 & $\begin{array}{l}1 \pm \\
1.1\end{array}$ & 1 & 0 & 3 \\
\hline 15 & 0? & 0 & 0 & 0 & $\begin{array}{l}1.2 \pm \\
0.84 \text { ? }\end{array}$ & 1 & 0 & 2 & $\begin{array}{l}1.17 \pm \\
0.41 \text { ? }\end{array}$ & 1 & 1 & 2 & $\begin{array}{l}0.83 \\
\pm \\
0.75 \text { ? }\end{array}$ & 1 & 0 & 2 \\
\hline
\end{tabular}

$* \mathrm{P}<0.05, \mathrm{G} 2$ vs. $\mathrm{G} 3$

$* * \mathrm{P}<0.05, \mathrm{G} 1$ vs. G3

$P<0.05, G 1$ vs.G2, G3, and G4

Mean $\pm s d=$ mean \pm standard deviation; $x=$ median; $\min =$ minimum value; max $=$ maximum value

In the assessments at days 4, 6, 8, 11, and 13 , the development of neovascularization in corneas from all groups was restricted to the limbal region (score 1), or extended from the limbal region to the edges of the cauterized site (score 2) (Table 2). 
The results of the corneal neovascularization profiles in all groups and at various times during the evaluation are described in Table 3.

Table 2 - Mean values with standard deviations, representing the development of neovascularization in the G1, G2, G3, and G4 groups, on days 2, 4, 6, 8, 11, 13, and 15 (Veterinary Ophthalmology Service, UNESP/FCAV, Jaboticabal, SP, Brazil 2017).

\begin{tabular}{lllll} 
Day & $\begin{array}{l}\text { G1 } \\
(\mathbf{n}=6)\end{array}$ & $\begin{array}{l}\text { G2 } \\
(\mathbf{n = 6})\end{array}$ & $\begin{array}{l}\text { G3 } \\
(\mathbf{n = 6})\end{array}$ & $\begin{array}{l}\text { G4 } \\
(\mathbf{n = 6})\end{array}$ \\
\hline 2 & $0^{*}$ & $1^{*}$ & $1^{*}$ & ---- \\
4 & 0 & $0.66 \pm 0.57$ & 1 & 1 \\
6 & $0.5 \pm 1$ & $1.33 \pm 0.57$ & 2 & $1.5 \pm 0.57$ \\
8 & $1.33 \pm 1.5$ & $2.25 \pm 1.5$ & 3 & $2.4 \pm 0.54$ \\
11 & $0.66 \pm 1.03$ & $1.4 \pm 1.51$ & $1.8 \pm 1.6$ & $2.5 \pm 1.22$ \\
13 & $0.5 \pm 1.22$ & $0.4 \pm 0.89$ & $1 \pm 1.5$ & 0 \\
15 & 0 & 0 & 0 & 0 \\
\hline
\end{tabular}

$* \mathrm{P}<0.05, \mathrm{G} 1$ versus $\mathrm{G} 2$ and $\mathrm{G} 3$

---- not assessed

Table 3 - Mean values with standard deviations, representing the corneal neovascularization profiles in the G1, G2, G3, and G4 groups, on days 2, 4, 6, 8, 11, 13 and 15 (Veterinary Ophthalmology Service, UNESP/FCAV, Jaboticabal, SP, Brazil 2017).

\begin{tabular}{|c|c|c|c|c|}
\hline Day & $\begin{array}{l}\text { G1 } \\
(n=6)\end{array}$ & $\begin{array}{l}\text { G2 } \\
(n=6)\end{array}$ & $\begin{array}{l}\text { G3 } \\
(n=6)\end{array}$ & $\begin{array}{l}\text { G4 } \\
(n=6)\end{array}$ \\
\hline 2 & $0^{*}$ & $1 *$ & $0.25 \pm 0.5^{*}$ & ---- \\
\hline 4 & 0 & $0.55 \pm 0.73$ & $0.5 \pm 0.57$ & $0.5 \pm 0.57$ \\
\hline 6 & $0.312 \pm 0.7^{* *}$ & $0.87 \pm 0.68$ & $1 \pm 1.15$ & $1.28 \pm 0.87^{* *}$ \\
\hline 8 & $1.21 \pm 1.32^{\circ}$ & $1.78 \pm 1.3$ & $2.6 \pm 0.96^{\circ}$ & $1.87 \pm 0.99$ \\
\hline 11 & $1.46 \pm 1.4^{2}$ & $2.27 \pm 1.23^{2}$ & $2.78 \pm 0.73^{2}$ & $2.62 \pm 1.01^{e}$ \\
\hline 13 & $1.5 \pm 1.5^{2}$ & $2.27 \pm 1.23^{2}$ & $2.83 \pm 0.64^{e}$ & $2.62 \pm 1.01^{e}$ \\
\hline 15 & $1.5 \pm 1.5^{e}$ & $2.22 \pm 1.22^{2}$ & $2.83 \pm 0.64^{e}$ & $2.62 \pm 1.01^{e}$ \\
\hline
\end{tabular}

*P $<0.05, \mathrm{G} 2$ vs. $\mathrm{G} 1$ and $\mathrm{G} 3$

$* * \mathrm{P}<0.05, \mathrm{G} 1$ vs. G4

${ }^{\circ} \mathrm{P}<0.05, \mathrm{G} 1$ vs. G3

'P $<0.05, G 1$ vs. G2, G3, and G4

---- not assessed

Our image analysis using the Image software, showed that corneas in the G3 group showed a larger percentage of vessels in the examined area, when compared with corneas in the $\mathrm{G} 1, \mathrm{G} 2$, and $\mathrm{G} 4$ groups ( $\mathrm{P}<0.05$ ) (Figure 2 ). 

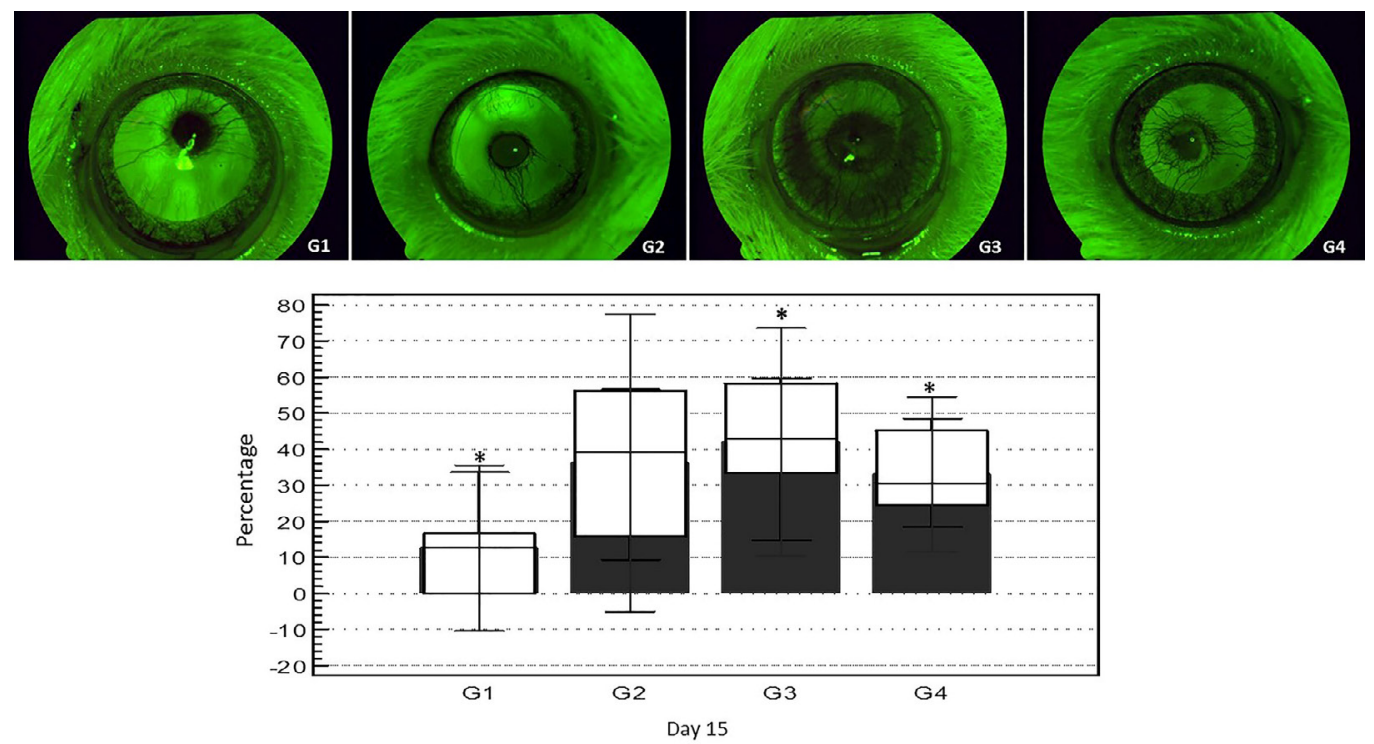

Figure 2 - A. Images of corneas with vessels, using a green filter (red free) in the G1, G2, G3, and G4 groups, on day 15 of the evaluation. B. Comparison between the percentages of the corneal area containing vessels in the G1, G2, $\mathrm{G} 3$, and G4 groups, on day 15 of the evaluation. ${ }^{*} \mathrm{P}<0.05$; $\mathrm{G} 1$ vs. $\mathrm{G} 3$ and G4 (Veterinary Ophthalmology Service, UNESP/FCAV, Jaboticabal, SP, Brazil 2017).

\section{- Discussion}

In vivo models for the study of the mechanistic basis of angiogenesis and for investigating the action of alleged antiangiogenic drugs should be affordable and non-invasive, when monitoring of the growth of new blood vessels. Rats are excellent model organisms for preclinical studies of angiogenesis, since they are small, easy to handle, incur a low cost, and have a mapped genome. The corneas of these animals have dimensions that allow rapid procedures for the induction of angiogenesis ${ }^{8,24}$.

To date, there is no consensus on the optimal protocol for the induction of corneal angiogenesis in rats ${ }^{10}$. The implantation of pellets containing drugs or pro-angiogenic molecules are emerging in the literature as reliable strategies. However, the vascular response associated with these procedures is very intense and unpredictable ${ }^{25}$. In addition, the investment required for pellet production is high. Alkaline cauterization remains the most widely used method for the induction of corneal angiogenesis, but its effectiveness may vary according to the protocol that is employed ${ }^{6,7}$. The lack of reproducibility represents a common problem, among studies involving models of angiogenesis induced by alkaline cauterization ${ }^{10}$.

The aim of this study was to establish a reproducible and inexpensive protocol for the induction of corneal neovascularization using alkali in rats, that is easy to perform, and presents a low risk of undesirable complications, such as the perforation of the eye. The alkaline cauterization produced in corneas in this study leads to a timely inflammatory response ${ }^{8,11-16}$, where the release of chemokines recruits leukocytes that produce angiogenic factors, such as the vascular endothelial growth factor, the fibroblast growth factor 2 and the tumor necrosis factor, among others. These growth factors attract endothelial cells, smooth muscle cells, fibroblasts, leukocytes, and platelets, triggering the process of neovascularization ${ }^{26}$.

In the USA, some biomedical 
laboratories sell disposable sticks coated with silver nitrate and potassium nitrate, suitable for corneal cauterization ${ }^{14,16}$. In Brazil, these sticks are not easily found, and need to be imported. Thus, we opted for preparing an aqueous solution containing $75 \%$ silver and $25 \%$ potassium nitrate, which was stored in an amber vial (protected from light) to avoid the oxidation of the compounds. For cauterization, filter papers were embedded in this alkaline solution and pressed onto the corneas of rats. The filter paper embedded with alkali used in this study, proved to be as effective, but more economical than commercial sticks.

The vascularization parameters were studied at different times for up to 15 days. In agreement with the literature, vessel growth tends to stabilize by the end of this period of time $^{8}$.

The corneal cauterization observed in this study was similar to that observed in previous reports ${ }^{8}$. Most of the eyes in the current study presented burn intensities of grades 2 and 3 . This result is similar to that reported by Hurmeric et $a .^{27}$ and HabotWilner et al. ${ }^{13}$, who used protocols in which the cauterization times were 8 and 10 seconds, respectively. These authors used commercial sticks to induce angiogenesis. We hypothesized that these commercially available coated sticks might be more concentrated. Therefore, this may explain the similarity between the values obtained in these studies and ours, as they used a shorter exposure time.

Groups whose corneas were exposed to alkali for a longer period of time presented higher values for the neovascularization profiles, that were either moderate or intense, as previously described by Yu et al. ${ }^{20}$. Interestingly, in our study, the vessels developed in a progressive manner until the eighth day post-cauterization in all study groups. In previous studies, vessel development ceased on the third day post-cauterization ${ }^{2}$.
In this study, larger corneal burns ( $3 \mathrm{~mm}$ ) were observed compared to those obtained in previous studies using sticks coated with silver and potassium nitrate $\mathrm{e}^{8,15}$. Thus, we expected the corneal fractions containing vessels to be much larger than those reported in previous studies. Interestingly, however, they were smaller. Sella et al. ${ }^{15}$ induced 2-mm burns and observed that the vascularized percentage of the corneal area was $42.6 \pm 19.59 \%$ on the $7^{\text {th }}$ day after the procedure. Manzano et $a l^{12}$ and Hepsen et al. ${ }^{11}$ induced cauterizations of $1.8 \mathrm{~mm}$ and $5 \mathrm{~mm}$, and observed vascularization in $63.5 \%$ and $56.9 \%$ of the corneal areas, respectively. We hypothesized that if these commercially coated sticks were more concentrated they could induce a greater inflammation, thus obtaining a larger corneal fractions containing vessels.

The time intervals during which the filter papers were in touch with the corneas changed the vascular response. On day 15 of the evaluation, these results differed significantly between the groups. The G3 and G4 groups showed intense neovascularization when compared with the $\mathrm{G} 1$ group. This suggested that the exposure time and maintaining the filter paper on the cornea at the time of washing, can modify the result, when corneas are compared at a later time.

\section{- Conclusions}

We demonstrated the efficacy of an aqueous solution composed of $75 \%$ silver and $25 \%$ potassium nitrate, for the induction of corneal angiogenesis in rats. Four protocols were studied, and three of these (G2, G3 and G4) provided consistent results, with good reproducibility. As well, we recommend the protocol G3, as a result of these group had the larger corneal neovascularization profiles and corneal fractions containing vessels. 


\section{References}

1. Auerbach, R, Lewis R, Shinners B, Kubai L, Akhtar N. Angiogenesis assays: a critical overview. Clin Chem. 2003 Jan;49(1):32-40. PMID: 12507958.

2. Fechine-Jamacaru FV, Fechine-Junior JU, Moraes-Filho MO. Model of inflammatory angiogenesis in rabbit cornea induced by punctual alkaline cauterization. Acta Cir Bras. 2005 Jan-Feb;20(1):64-73. PMID: 15810467.

3. Pandya NM, Dhalla NS, Santani DD. Angiogenesis a new target for future therapy. Vascul Pharmacol. 2006 May;44(5):265-74. PMID: 16545987.

4. Jaffe RB. Importance of angiogenesis in reproductive physiology. Semin Perinatol. 2000 Feb;24(1):79-81. PMID: 10709866.

5. Polverini PJ. Angiogenesis in health and disease: insights into basic mechanisms and therapeutic opportunities. J Dent Educ. 2002 Aug;66(8):962-75. PMID: 12214844.

6. Trujillo Piso $D Y$, Ribeiro $A P$, Silva $M L$, Guimarães PJ, Morales A., Martins BC, Padua IM, Renzo R, Andrade AL, Uscátegui RR, Laus JL. Vet Ophthalmol. 2014 Jan;17(1):23-31. PMID: 23433350.

7. Papathanassiou $M$, Theodossiadis PG, Liarakos VS, Rouvas A, GiamarellosBourboulis EJ, Vergados IA. Inhibition of corneal neovascularization by subconjunctival bevacizumab in an animal model. Am J Ophthalmol. 2008 Mar;145(3):424-31. PMID: 18207123.

8. Akar EE, Öner V, Küçükerdönmez C, Akova YA. Comparison of subconjunctivally injected bevacizumab, ranibizumab, and pegaptanib for inhibition of corneal neovascularization in a rat model. Int J Ophthalmol. 2013;6(2):136-40. doi: 10.3980/j.issn.22223959.2013.02.05.

9. Koenig Y, Bock F, Horn F, Kruse F, Straub K, Cursiefen C. Short- and long-term safety profile and efficacy of topical bevacizumab (Avastin ${ }^{\circledR}$ ) eye drops against corneal neovascularization. Graefes Arch Clin Exp Ophthalmol. 2009 Oct;247(10):1375-82. PMID: 19415316.

10.Norrby K. In vivo models of angiogenesis. J Cell Mol Med. 2006 Jul;10(3):588-612. PMID: 3933145.

11. Hepşen IF, Er H, Çekiç O. Topically applied water extract of propolis to suppress corneal neovascularization in rabbits. Ophthalmic Res. 1999;31(6):426-31. PMID: 10474071.

12. Manzano RP, Peyman GA., Khan P, Carvounis PE, Kivilcim M, Ren M, Lake JC, Chévez-Barrios P. Inhibition of experimental corneal neovascularization by bevacizumab (Avastin). $\mathrm{Br} J$ Ophthalmol. 2007 Jun;91(6):804-7. PMID: 1955569.

13. Habot-Wilner Z, Barequet IS, Ivanir Y, Moisseiev J, Rosner M. The inhibitory effect of different concentrations of topical bevacizumab on corneal neovascularization. Acta Ophthalmol. 2010 Dec;88(8):862-7. PMID: 19549103.

14.Ozdemir O, Altintas O, Altintas L, Ozkan B, Akdag C, Yüksel N. Comparison of the effects of subconjunctival and topical anti-VEGF therapy (bevacizumab) on experimental corneal neovascularization. Arq Bras Oftalmol. 2014 Aug;77(4):209-13. PMID: 25410169.

15.Sella R, Gal-Or O, Livny E, Dachbash M, Nisgav $Y$, Weinberger $D$, Livnat $T$, Bahar, I. Efficacy of topical aflibercept versus topical bevacizumab for the prevention of corneal neovascularization in a rat model. Exp Eye Res. 2016 May;146:224-32. PMID: 27020759.

16.Schaap-Fogler M, Bahar I, Rephaeli A, Dahbash M, Nudelman A, Livny E, Barliya T, Nisgav $Y$, Livnat, T. Effect of histone deacetylase inhibitor, butyroyloxymethyldiethyl phosphate (AN-7), on corneal neovascularization in a mouse model. $\mathrm{J}$ Ocul Pharmacol Ther. 2017 Jul/Aug;33(6):480-6. doi: 10.1089/jop.2016.0017.

17. Claros-Chacaltana FDY, Kobashigawa KK, Padua IRM, Valdetaro GP, Aldrovani M, Laus JL. Persistent pupillary membrane in Wistar laboratory rats (Rattus Norvegicus, Albinus Variation, Wistar). Ciênc Rural. 2017;47(3). doi: 10.1590/0103-8478cr20160421

18. Mohan RR, Stapleton WM, Sinha S, Netto MV, Wilson SE. A novel method for generating corneal haze in anterior stroma of the mouse eye with the excimer laser. Exp Eye Res. 2008 Feb; 86(2): 235-40. doi: 10.1016/j.exer.2007.10.014.

19. Mahoney JM, Waterbury LD. Drug effects on the neovascularization response to silver nitrate cauterization of the rat cornea. Curr Eye Res. 1985 May;4(5):531-5. PMID: 
2410194.

20.Yu H, Wu J, Li H, Wang Z, Chen X, Tian Y, $Y i X, M a J$, Huang $Q$. Inhibition of corneal neovascularization by recombinant adenovirus-mediated sFlk-1 expression. Biochem Biophys Res Commun. 2007 Oct 5;361(4):946-52. PMID: 17692288.

21.Yamada J, Dana MR, Sotozono C, Kinoshita S. Local suppression of IL-1 by receptor antagonist in the rat model of corneal alkali injury. Exp Eye Res. 2003 Feb;76(2):161-7. PMID: 12565803.

22.Kang S, Chung SK. The effect of subconjuctival combined treatment of bevacizumab and triamcinolone acetonide on corneal neovascularization in rabbits. Cornea. 2010 Feb;29(2):192-6. PMID: 20098156.

23.Bock F, Onderka J, Hos D, Horn F, Martus P, Cursiefen C. Improved semiautomatic method for morphometry of angiogenesis and lymphangiogenesis in corneal flatmounts. ExpEye Res. 2008 Nov;87(5):46270. PMID: 18789928.

24.Safatle ADMV, Barros PSDM, Malucelli BE,
Guerra JL. Implantation of two biological membranes in a corneal micropocket as an experimental model for angiogenesis. Braz J Vet Res An Sci. 2002;39(4):189-95. doi: 10.1590/S1413-95962002000400005.

25.González RP, Leyva A, Melo RA, Moreira RD, Pessoa C, Farias RF, Moraes MO. Método para o estudo in vivo da angiogênese: indução de neovascularização na córnea de coelho. Acta Cir Bras. 2000 Sep;15(3). doi: 10.1590/S0102-86502000000300006.

26. Ribeiro JC, Fechine FV, Ribeiro MZ, Barreiro EJ, Lima LM, Ricardo NM, De Moraes ME, De Moraes MO. Potential inhibitory effect of LASSBio-596, a new thalidomide hybrid, on inflammatory corneal angiogenesis in rabbits. Ophthalmic Res. 2012;48(4):17785. PMID: 22777402.

27. Hurmeric V, Mumcuoglu T, Erdurman C, Kurt B, Dagli O, Durukan AH. Effect of subconjunctival bevacizumab (Avastin) on experimental corneal neovascularization in guinea pigs. Cornea. 2008 Apr 1;27(3):35762. PMID: 18362668.

\section{Correspondence:}

Flor Diana Yokoay Claros Chacaltana

Serviço de Oftalmologia, Departamento de Clínica e Cirurgia Veterinária

Faculdade de Ciências Agrárias e Veterinárias, UNESP, Campus de Jaboticabal

Rua Prof. Paulo Donato Castellane, s/n

14884-900 Jaboticabal - SP Brasil

Tel.: (55 16)3209-7100

florclaros@hotmail.com

Received: Apr 19, 2017

Review: June 20, 2017

Accepted: July 18, 2017
Conflict of interest: none

Financial sources: CNPQ (Proc. 300833/2010-5), and FAPESP (Proc. 2009/51773-4)

\footnotetext{
${ }^{1}$ Research performed at Laboratory of Ophthalmology Service, Department of Clinical and Veterinary Surgery, Faculty of Agrarian and Veterinary Sciences, Universidade Estadual de São Paulo (FCAV-UNESP), Jaboticabal-SP, Brazil. Part of PhD degree thesis, Postgraduate Program in Veterinary Surgery. Tutor: José Luiz Laus.
} 